\title{
Apical microleakage of epoxy resin and methacrylate resin-based sealer with continuous wave obturation technique
}

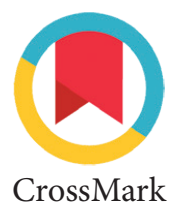

\author{
Haslinda, Christine A. Rovani, Aries C. Trilaksana*
}

\section{Abstract}

Objective: The aim of this research was to determine the microleakage of apical sealer based on epoxy resin and methacrylate resin with continuous wave obturation technique.

Material and Methods: Thirty permanent lateral incisors were selected randomly and divided into 3 groups. The samples were decoronated, the root canal was prepared and then the samples were kept in incubator at $37^{\circ} \mathrm{C}$ for 72 hours. The sample were coated with nail varnish then immersed in methylene blue for 48 hours. The samples were washed with distilledwater, dried and nailvarnish was removed. The samples were clearing and the penetration was measured using microscope and given score $0-4$. Measurements were analyzed statistically using Kruskal-Wallistest and MannWhitney test.

Results: There was no significant difference between the apical microleakage of the the epoxy resin-based root canal sealer with methacrylate resin-based root canal sealer $(p>0.05)$. It means that the apical microleakage of the epoxy resin-based root canal sealer is comparable with methacrylate resin-based root canal sealer. Conclusion: It is concluded that the apical microleakage of epoxy resin-based sealer does not differ from the methacrylate resin-based sealer.
Department of Conservative Dentistry, Faculty of Dentistry, Hasanuddin University, Makassar, Indonesia

*Correspondence to: Aries Chandra Trilaksana, Department of Conservative Dentistry, Faculty of Dentistry, Hasanuddin University, Makassar, Indonesia aries_dent@gmail.com

Received: 09 March 2016 Revised: 25 April 2016 Accepted: 26 April 2016 Available Online: 30 April 2016

Keywords: Apical microleakage, Epoxy resin sealer, Methacrylate resin sealer Cite This Article: Haslinda, Rovani CA, Trilaksana AC. 2016. Apical microleakage of epoxy resin and methacrylate resin-based sealer with continuous wave obturation technique. Journal of Dentomaxillofacial Science 1(1): 20-24. D0I: 10.15562/jdmfs.v1i1.19

\section{Introduction}

Obturation of root canal is the last stage of root canal care. It aims to prevent the microorganism from re-infecting and to kill the remaining pathogenic bacteria in the root canal system..$^{1-3}$ If obturation does not cover the whole root canal system well, the microorganism can enter, develop and may cause "Bacteremia Transient" which results to failure in the root canal care. One of the standard obturation materials used recently is gutta-percha, which does not adhere well on dentine. Therefore, a sealer is required to cover space between gutta-percha and root canal buttress. ${ }^{7-9}$

Various sealer will be available in the market, such as sealer with zinc oxide eugenol materials, calcium hydroxide, Glass Ionomer Cement (GIC) and resin. ${ }^{3,9}$ Some researches clarify that recently, sealer with epoxy resin has a good radiopacity, low solubility, good adaptation toward the root canal buttress and good ability of apical covering. However, due to condition of imperfect polymerization if the sealer comes in contacts with tissue, it will cause acute inflammation. ${ }^{4,5,10,11}$

Referring to the disadvantages of epoxy resin sealer, a new resin cement with methacrylate resin materials needs to be developed. One of the research outcomes indicated that methacrylate resin sealer has longer resin tag compared to that of epoxy resin as well as a hydrophilic characteristic so that it has a better adaptation on the root canal area with a good adaptability of tooth supporting tissue.

In addition, there are some techniques to perform the obturation of the root canal. The most commonly used obturation technique is the solid core technique. However, some researches clarified that this technique has some disadvantages. The weakness of this solid core technique can be covered by the softened core obturation technique. One of the softened core obturation techniques is the continuous wave technique. It has some advantages such as the homogeneous mass of gutta-percha, good adaptation in root canal buttress, therefore, it only requires a few sealer with the ability to fill the whole root canal system, the penetration to accesory and lateralis canal and diminish the working time.

According to the explanation, it is necessary that a research is conducted to understand what will occur if methacrylate resin and epoxy resin sealer are administered in continuous wave obturation technique. The objective of this research was to reach hermetis stage of obturation using resin sealer with continuous wave obturation technique, recognizing that one of failures of the root canal care is caused by the unhermitic obturation. 


\section{Material and Methods}

All samples which have met the inclusion criteria and became appropriate with big estimation of sample with big estimation of sample that were decoronated until Cementoenamel Junction (CEJ) area. Preparation of root canal was performed using crown-down pressureless technique with ProTaper rotary files (Dentsply Mailefer, Ballagigues, Switzerland) until the F4. Irrigation using $\mathrm{NaOCl} 2.5 \%$ and EDTA 17\% was performed in each file substitution and aquadest was used as the last rinsing material.

After preparation the root canal was drained with paper point and the samples were divided into 3 groups each of which consisted of 10 teeth. Thirty teeth of permanent lateralis insisivus of upper jaw were chosen randomly. The first group was obturated with epoxy resin sealer (AH Plus, Dentsply maillefer, Swiss), the second group was administered with methacrylate resin sealer material (EndoREZ, Ultradent Corp) and the third group as negative control was prepared but was not obturated. The negative control group was also not covered with nail polish. Obturation of $\mathrm{F} 4$ root canal involving the gutta-percha utilization used continuous wave technique, where the sealer in root canal was earlier prepared using lentulo pin. The thickness of filling was controlled through radiograph. After filling was appropriate and compact, the root canal was then covered with composite resin (3M ESPE, US).

After that, all samples were placed in specimen bottle and stored in incubator at $37^{\circ} \mathrm{C}$ for $3 \times 24$ hours.
Then, all of the first and the second group sample were layered using nail polish to obtain two layers, left $2 \mathrm{~mm}$ from apex uncovered. Sample of negative control group was not layered by nail polish. All samples were then soaked in methylene blue for $2 \times 24$ hours at the room temperature. Then, the sample was taken out and washed with flowing water and the nail polish layer was separated with aceton then placed in specimen bottle at the room temperature for $1 \times 24$ hour. All samples were soaked in $10 \%$ of nitric acid for $3 \times 24$ hours, then soaked in $70 \%, 90 \%$ and $100 \%$ alcohol respectively for 30 minute. Clearing step was done by soaking the specimen in methyl salicylate.

The depth of methylene blue penetration was evaluated from apical to coronal position using light microscope, with the certainty score of 0 if there was no penetration, it was scored 1 if the methylene blue penetrates less than $0.5 \mathrm{~mm}$, scored 2 if the methylene blue penetrates $0.5-1$ $\mathrm{mm}$, scored 2 if the methylene blue penetrates 1-2 mm, scored 2 if the methylene blue penetrates more than $2 \mathrm{~mm}$.

\section{Results}

According to the observation of 30 roots of permanent incisivus lateralis teeth of upper jaw that have fulfilled the sample criteria, the ratio of apical microleakage from sealer of epoxy resin materials with methacrylate resin material, were the counted leakage score of $1 / 3$ on profundity of methylene blue penetration from apical to coronal restructuring.

Table 1 Connection between kind of sealer resin with category of penetration profundity (apical microleakage)

\begin{tabular}{|c|c|c|c|c|c|c|c|}
\hline \multirow[b]{3}{*}{ Type of Sealer } & \multicolumn{5}{|c|}{ Result of Apical Microleakage Category } & \multirow[b]{3}{*}{ Total } & \multirow[b]{3}{*}{$p$ value } \\
\hline & Score 0 & Score 1 & Score 2 & Score 3 & Score 4 & & \\
\hline & n (\%) & n (\%) & n (\%) & n (\%) & n (\%) & & \\
\hline Epoxy resin & $0(0 \%)$ & $7(70 \%)$ & $3(30 \%)$ & $0(0 \%)$ & $0(0 \%)$ & $10(33.3 \%)$ & \\
\hline methacrylate resin & $0(0 \%)$ & $10(100 \%)$ & $0(0 \%)$ & $0(0 \%)$ & $0(0 \%)$ & $10(33.3 \%)$ & $0.000^{*}$ \\
\hline Negative control & $0(0 \%)$ & $0(0 \%)$ & $0(0 \%)$ & $10(100 \%)$ & $0(0 \%)$ & $10(33.3 \%)$ & \\
\hline Total & $0(0 \%)$ & $17(56.7 \%)$ & $3(10 \%)$ & $10(33.3 \%)$ & $0(0 \%)$ & $30(100 \%)$ & \\
\hline
\end{tabular}

* chi-square: $p<0.05$; significant

Table 2 Differences of apical microleakage profundity between obturation with sealer of basic epoxy resin, methacrylate resin and negative control

\begin{tabular}{lccc}
\hline & & Apical Microleakage (mm) \\
Type of sealer resin & $\mathbf{n}(\%)$ & Mean \pm SD & $0.310 \pm 0.247$ \\
\hline Epoxy resin & $10(33.3)$ & $0.140 \pm 0.069$ \\
methacrylate resin & $10(33.3)$ & $2.000 \pm 0.000$ \\
Negative control & $10(33.3)$ & $0.817 \pm 0.865$ \\
Total & $30(100)$ & $0.000^{* *}$ \\
\hline
\end{tabular}

* Shapiro-Wilk test: $p<0.05$; normal distribution

${ }^{* *}$ Kruskal-Wallis test: $p<0.05$; significant 
Table 3 Outcome of Mann-Whitney examine measure apical microleakage profundity between epoxy resin, methacrylate resin and negative control

\begin{tabular}{lccc}
\hline Resin sealer $(\mathbf{i})$ & Ratio $(\mathbf{j})$ & Mean Difference $(\mathbf{i}-\mathbf{j})$ & $\boldsymbol{p}$ value \\
\hline Epoxy resin & Methacrylate resin & 0.1700 & 0.146 \\
& Negative control & -1.6900 & $0.000^{\star}$ \\
Methacrylate resin & Negative control & -1.8600 & $0.000^{\star}$ \\
\hline
\end{tabular}

${ }^{*}$ non-parametric Pos Hoc Test: Mann Whitney: $p<0.05$ : meaningful

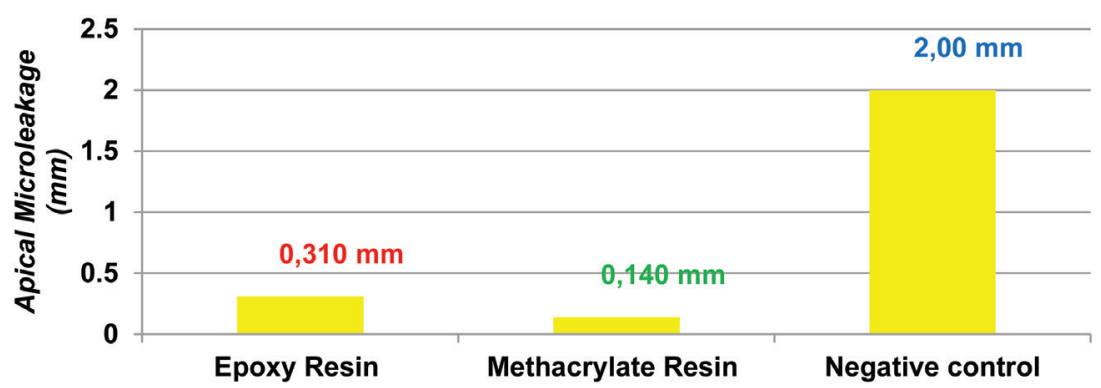

Figure 1 Distribution of apical microleakage profundity based on the types of resin sealer

Table 1 shows leakage of epoxy resin groups was bigger than sealer of methacrylate resin. Methylene blue penetration of all methacrylate resin group indicated a score of 1 (100\%). Whereas, about $70 \%$ methylene blue penetrations of epoxy resin group indicated score 1 and $30 \%$ indicated score 2 , there was no methylene blue penetration in score 3 and 4 . While all of sample of negative control group indicated score 3. Table 2 and figure 1 shows the difference of apical microleakage profundity in all of sample. The research result showed that the average of group 3 of apical microleakage was the highest than the other. In addition, it was also observed that group 2 had the lowest apical microleakage than others, which had average value of $0.14 \mathrm{~mm}$. Meanwhile, in group 1 the apical microleakage average value was $0.31 \mathrm{~mm}$ the research of Kruskal-Wallis indicated a $\mathrm{p}$-value of 0.000 , which means there was a significant difference about apical microleakage among group 1 , group 2 and group $3(\mathrm{p}<0.05)$.

The result of the continued observation indicated that the difference between group 1 and group 3 as well as group 2 and group 3 were significant $(\mathrm{p}<0.05)$. However, if the group 1 was compared to the group 2, we will obtain that the difference of apical microleakage is $0.17 \mathrm{~mm}$. However, statistical result indicates that it is not significant ( $>0.05)$.

The post-hoc test results in table 3 shows that the difference between groups 1 and 3 , as well as group 2 and 3 was significantly different $(p<0.05)$. However, if the group 1 is compared to the group 2, we will obtained the difference in deviation of $0.17 \mathrm{~mm}$ of the apical microleakage. But the result of statistical tests showed that it is not significant ( $p>0.05)$.

\section{Discussion}

Apical microleakage is one of the initial causes of a root canal treatment failure, occurred due to inadequate obturation of root canal. Apical microleakage occurs on the surface of the sealer with dentin or with gutta-percha. ${ }^{14,15}$

The results of this study showed that all the samples in the study group experienced apical microleakage. Apical microleakage is characterized by the penetration of methylene blue table 1 and figure 1 . The percentages of apical microleakage can be observed by the score of group 1 (AH Plus), group 2 (EndoRez) and group 3 (negative control). A total of $56.7 \%$ of the samples are in the score of 1 , about $10 \%$ of the samples are in a score of 2 and about $33.3 \%$ of samples were in the score of 3 . There was no sample which was observed in a score of 0 . The percentage of samples were not observed in a score of 4 that passes through the penetration of more than $2 \mathrm{~mm}$, due to the limits of the nail polish penetrtion before it is soaked in methylene blue is $2 \mathrm{~mm}$ to the apical.

Apical microleakage occurs on resin-based sealer of two study groups due to the natural properties of the sealer made from resin, that is the occurrence of shrinkage during polymerization. Shrinkage will cause the main contact between the filler and the root canal wall at first meeting which frays. ${ }^{4,5,16}$

This is in line with the research conducted by Kumar and Shivani. ${ }^{17}$ Which is compared with the apical sealing ability and adaptability of the type of hydrophobic and hydrophilic resin sealer on the market. All resin sealer samples reveal poor adaptation to the dentin, as well as the penetration of dye more in the apical region compared coronal. ${ }^{17}$

Shrinkage stress is a major problem in the attachment of the root canal resin sealer, and mainly occurs in the deep and narrow root canals. Shrinkage occurs faster when the proportion of sealer that does not bind to the free surface area is greater than that of the high one called C-factor. This condition will create residual stress or debonding and leakage. Further, nonbonded resin sealer will absorb the excessive amount of water that cause the disintegration of the sealer, so that the high $\mathrm{C}$-factor is a major obstacle to eliminating gap from the sealer attachment. ${ }^{4,5,17}$

There are several parameters that affects shrinkage stress: the degree of shrinkage polymerization volume of the resin sealer, elasticity modulus of dentin, root canal filling, air in sealer when stress occurs, as well as the expansion or contraction of root canal filling when heat is associated. ${ }^{3,5,18,19}$

Beside the character of the shrinkage in resin sealer, the cause of the apical microleakage in both groups of samples are possibly caused by the 
presence of micro air bubbles of gas in the apex. This is due to the $\mathrm{NaOCl}$ reaction to organic material in the root canal, causing irrigation activity of EDTA which does not effectively remove inorganic material from the smear layer. Irrigation techniques using a machine with agitation system will be able to overcome the effects of $\mathrm{NaOCl}$, but in this study the irrigation technique used is the manual system. ${ }^{20}$

Although apical microleakage occurred in two groups of the study, the results showed the smallest mean apical microleakage of EndoRez group among the other groups, with an average of $0.14 \mathrm{~mm}$ leakage. While AH Plus group has a mean of $0.31 \mathrm{~mm}$ leakage. The control group was the highest of $2.0 \mathrm{~mm}$.

Methacrylate resin group has the smallest apical microleakage value. This may be caused by some physical characters of this sealer, including natural hydrophilic character of phosphate esters contained in UDMA. This composition can get into the damp dentin walls. The other physical characteristics are film thickness and a small filler particle size that is able to penetrate the dentinal tubules further than epoxy resin sealer. Resin tags formed by natural hydrophilic material are capable of forming a tissue that is $800-1200 \mu \mathrm{m}$ in long. ${ }^{3,12}$

EndoREZ, the dual core resin sealer that is influenced by the flow of resin polymerizes slowly. These characteristic can reduce the occurrence of shrinkage stress. The shrinkage stress reduction by resin flow depends on the film thickness. The thinner the sealer film, thesmaller the shrinkage stress that occurs because of polymerization. ${ }^{10,21}$

The results in table 2 is parallel that evaluates the apical sealing ability of AH Plus resin sealer and EndoRez with lateral condensation obturation techniques assessed by SEM, who declares that the resin tags on EndoRez is longer than AH Plus. He said that the hydrophilic character and small particle size of the filler EndoREZ resin capable of forming a hybridization tag, while the $\mathrm{AH}$ Plus sealer containing silicone oil which may prevent the root canal wall from complete wetting. ${ }^{12}$

In this study, continuous wave obturation techniques were performed in charging technique because it was capable to produce more mass homogenicity of gutta-percha, but obturation techniques expressed by Cavenago and Duarte does not affect the apical microleakage. They reported that the interfacial adaptation between resin sealer against dentin root canal using single cone obturation and system B techniques. The results indicate that the gap formed between the two obturation techniques is not significantly different on the utilization of resin sealer. ${ }^{22}$
The differences of apical microleakage in A Plus and EndoREZ groups on different post-test by Mann-Whitney, did not show significant values ( $p>0.05)$. It can be revealed from table 3, that the difference of value between apical microleakage is quite small about $0.17 \mathrm{~mm}$ between the two groups. It showed that the sealer ability to minimize the occurrence of apical microleakage which was not significantly different.

The evaluated apical microleakage off our different types of sealer. Their conclusions stated that the insignificant results of these difference studies are caused by the physical properties of each sealer. Methacrylate resin is a hydrophilic resin that well adapts in a moist environment of root canal and capable of forming a long resin tags. While the epoxy resin that is dimensionally stable, has a good apical sealing ability. ${ }^{22,24}$

Changes in sealer dimensions based on ISO standard, is named shrinkage $\leq 1.0 \%$ and $\leq 0.1 \%$ expansion. The dimensional changes in both groups of sealer in this study were under a set value based on ISO standards. However, the epoxy resin has a value change in dimensions which is smaller than the methacrylate type of resin sealer. ${ }^{23,24}$

\section{Conclusion}

Concluded that the apical microleakage of sealer made from an epoxy resinand methacrylate resin with continuous wave obturation technique is not statistically different. Based on the limitations of this study, it is suggested that further studies are conduct with different methods and longer evaluation time.

\section{Conflict of Interest}

The authors report no conflict of interest.

\section{References}

1. Sobhani AM, Ghorbanzadeh A, Bolhari B. Coronal microleakage in root canals obturated with lateral compaction, warm vertical compaction and guttaflow system. Int Endod J 2010;5: 83-88.

2. Grossman LI, Oliet S, Del Rio CE. Ilmu endodontik dalam praktek. Jakarta: EGC; 2008. p. 286.

3. Wesseling P. Root filling techniques. In: Bergenholtz G, Preben HB, Claes R. Editors. Text book of endodontology. 2nd Ed. Philadelphia: Willey Blackwell; 2010. p. $321-325$.

4. Tanh N, Ruddle J. Obturation of the root canal systems. In: Cohen S, Burn RC. Editors. Pathway of the pulp. 6th Ed. Philadelphia: Willey Blackwell; 2005. p. 245-248.

5. Walton R, Torabinejad M. Principles and practice of endodontics. 3rd Ed. Philadelphia: WB Saunders; 2002. p. 111114, 263-266, 352-357.

6. Siqueira JF. Aetiology of root canal treatment failure: whywell-treated teeth can fail. Int Endod J 2001;34: 1-10. 
7. Mittal R, Singla MG, Garg A. Comparative analysis of apical microleakage for two obturating materials-resilon and gutta-percha with two resin-based sealers. Saudi Endod J 2012;2: 14-18.

8. Calcedo R, Clark SM. Modern perspective in root canal treatment. (serial on internet) 2007 (cited 2014 sept 1). Available from: URL: http://www.devosendo.nl/may/inedeece.htm.

9. Henston JDL, Sarma N, Subhash C. Root canals sealers \& its role in successful endodontics-a review. Ann Dent Res 2012;2: 68-78.

10. Tyagi S, Mishra P, Tyagi P. Evolution of root canal sealers: an insight story. Eur J Gen Dent 2014;2: 199-210.

11. Mahajan VA, Kamra AL. An in-vitro of apical sealing of three epoxy resin-based commercial preparations. Endodontol 2012;4: 9-12.

12. Kumar NS, Palanivelu A, Narayanan L. Evaluation of the apical sealing ability and adaptation to the dentin of two resin-based sealers: an in vitro study. J Conserv Dent 2013;16: 449-453.

13. Kandaswamy D, Venkateshbabu N, Krishna RG. Comparison of laterally condensed, vertically compacted thermoplasticized, cold free-flow GP obturations- a volumetric analysis using spiral CT. J Conser Dent 2009;12: 145-149.

14. Tanikonda R, Sekhar SK, Anupreeta A. Flowable gutta-percha in endodontics- review and few case reports. J Res Adv Dent 2013;2: 86-90.

15. Ruddle CJ. Three-dimensional obturation of the root canal system. Dent Today 2006;2: 1-11.

16. Wong JG, Caputo AA. Microleakage of adhesive resinous materials in root canals. J Conserv Dent 2013;16: 213-219.

17. Kumar AS, Shivanna V. Comparative evaluation of the apical sealing ability and adaptation to dentine of three resin-based sealers: an in vitro study. J Conserv Dent 2011;14: 16-20.

18. Rajput JS, Pathak A. An evaluation of sealing ability of endodontic material as root canal sealers. Root canal sealing ability of endodontic materials 2009;2: 1-7.

19. Adanir N, Cobankara FK, Belli S. Sealing properties of different resin-based root canal sealers. Wiley Intersci J 2005;3: 1-5.

20. Farhad AR, Barekatain B, Koushki AR. The effect of three different root canal irrigant protocols for removing smear layer on the apical microleakage of AH 26 sealer. Int Endod J 2008;3: 62-68.

21. Tay FR, Loushine RJ. Effectiveness of resin-coated gutta-percha cones and dual-cured, hydrophilic methacrylate resin-based sealer in obturating root canals. J Endod 2005;31: 659-664.

22. Cavenago BC, Duarte MAH. Interfacial adaptation of an epoxy resin sealer and a self-etch sealer to root canal dentin using the system $\mathrm{B}$ or the single cone technique. Braz Dent J 2012;23: 205-211.

23. Leal FM, Camargo CHR. Coronal bacterial leakage in root canals filled with single cone technique and different endodontic sealers. Braz Dent Sci 2014;17: 57-63.

24. Yigit DH, Gencoglu N. Evaluation of resin/silicone-based root canal sealer. Part 1: physical properties. Digest J Nanomater Biostruct 2012;7: 107-115.

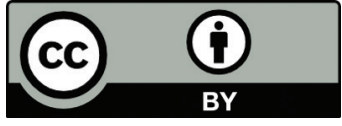

This work is licensed under a Creative Commons Attribution 